\title{
THE ELECTRON LINAC ON THE BASIS OF SYSTEM WITH NONSYNCHRONOUS WAVES FOR NUCLEAR GEOPHYSICS
}

\author{
$\underline{\text { B. Bogdanovitch }}{ }^{1}$, A. Nesterovitch, S. Stepanov, MEPhI, Moscow, Russia
}

\begin{abstract}
In nuclear geophysics the chinks carottage at the minerals search by means of radiation occurring in a ground with presence of bremsstrahlung produced by electron linac (Compton effect, $\gamma-\gamma^{\prime}$ reaction) is widely known. An induction electron linacs of LIA-0,5/50 type developed in Institute of the Electrophysical Equipment (St.Petersburg) have got the greatest advancement in Russia. Such devices have a diameter no more than $10 \mathrm{~cm}$, length about $3 \mathrm{~m}$, electron current up to $50 \mathrm{~A}$, electron energy about $0,5 \mathrm{MeV}$ and pulse duration of $50 \mathrm{~ns}$. Linac, power supply system and control equipment are displaced in the same cylindrical module. The electric power is supplied through cable from a source placed on a ground surface. The signals from the control equipment are transmitted to the ground board [1]. A lack of such system is the rather small efficiency, that is characteristic for induction linacs, and limited service life in conditions of high temperatures (up to $+2000 \mathrm{C}^{0}$ ), caused by degradation of ferrite cores of accelerating structure.

In the report given the results of preliminary research of the electron linac based on an auto resonant acceleration principle are described. Such linacs have certain restrictions on energy and acceleration rate, but are represented as most effective for the geophysics tasks decision by specific differences of single resonator accelerating system [2].
\end{abstract}

\section{THE DEVICE DESIGN}

The principle of the accelerator action consists in RF fields generation by cyclotron resonance maser type system. The scheme of the device is shown on Fig.1.

The device operates in the following way. The tubular shaped electron flow, emitted the cathode 1 , gets into accelerating space between cathode and resonator 2 and begins to rotate as whole in the longitudinal magnetic field of solenoid 3. Thus significant part of longitudinal electron energy transforms into a rotary movement energy. The rotating electron flow gets into the resonator 2 and excites RF electromagnetic $\mathrm{TE}_{01 \mathrm{n}}$ mode in it.

The significant part of electrons gives back their energy to a RF field so electron beam radius of rotation decreases, as it is shown in [3]. These particles gets on a central part of a collimator 5 . The accelerating resonator 6 is connected by coupling cells 4 to the generating resonator 2, therefore a RF field of a similar type also is exited in it. In collimator 5 area magnetic field comes to zero, so the electron trajectories become rectilinear, parallel to a longitudinal axis. Then the insignificant part of electron flow, not captured in a generation mode and having the greatest energy and rotation radiuses, gets into accelerating section 6 .

If magnetic field induction increases upon length this part of electron beam is accelerated by means of nonsynchronous waves of $\mathrm{TE}_{01 \mathrm{n}}$ mode up to energy about $0.8 \mathrm{MeV}$. Thus the electrons accelerated get onto a tungsten target 7 placed on lateral waveguide walls, producing a flow of bremsstrahlung (or $\gamma$ - radiation) in a transverse direction. The back scattered radiation from the ground is registered by the detector (not shown in a Fig. 1). The face wall 8 of the accelerating resonator is designed mobile, it's displacement is defined automatically by condition of a resonators 2 and 6 frequencies resonance. It is carried out by the reversal engine 9, controlled automatically by comparison of signals from two detectors (are not shown in a Fig. 1). If a frequency is deviated due to heating the automatic tuning of a magnetic field value by change of a solenoids current is carried out.

\section{LINAC CALCULATED PARAMETERS}

Generating and accelerating sections represent rectangular resonators with the cross sizes $44 \mathrm{~mm} \times 72 \mathrm{~mm}$ (operating frequency $\sim 2800 \mathrm{MHz}$ ). The length of generating section is equal to $0.2-0.3 \mathrm{~m}$, and accelerating section has length about $1 \mathrm{~m}$. The injection current is equal to $40 \mathrm{~A}$ (after collimator - $0.5 \mathrm{~A}$ ), injection voltage is equal to $50 \mathrm{kV}$, the pulse duration is equal to $2 \mu \mathrm{s}$, the repetition rate is about $50 \mathrm{~Hz}$. The accelerating harmonic amplitude makes $50 \mathrm{kV} / \mathrm{cm}$, pulsed accelerated current at an linac output - $0.1 \mathrm{~A}$. The magnetic field is equal to $0,05 \mathrm{~T}$ in generating section. In accelerating section the magnetic field raises from 0.05 up to $0.12 \mathrm{~T}$. Electrons get on the tungsten target, thus producing a bremsstrahlung flow with intensity up to 1.5 $\mathrm{rad} /$ hour. The cross dimensions of whole device does not exceed $0.14 \mathrm{~m}$, length (with the power supply system and detector) is no more than $3 \mathrm{~m}$.

\footnotetext{
${ }^{1}$ E-mail: bogdan@uni.mephi.ru
} 

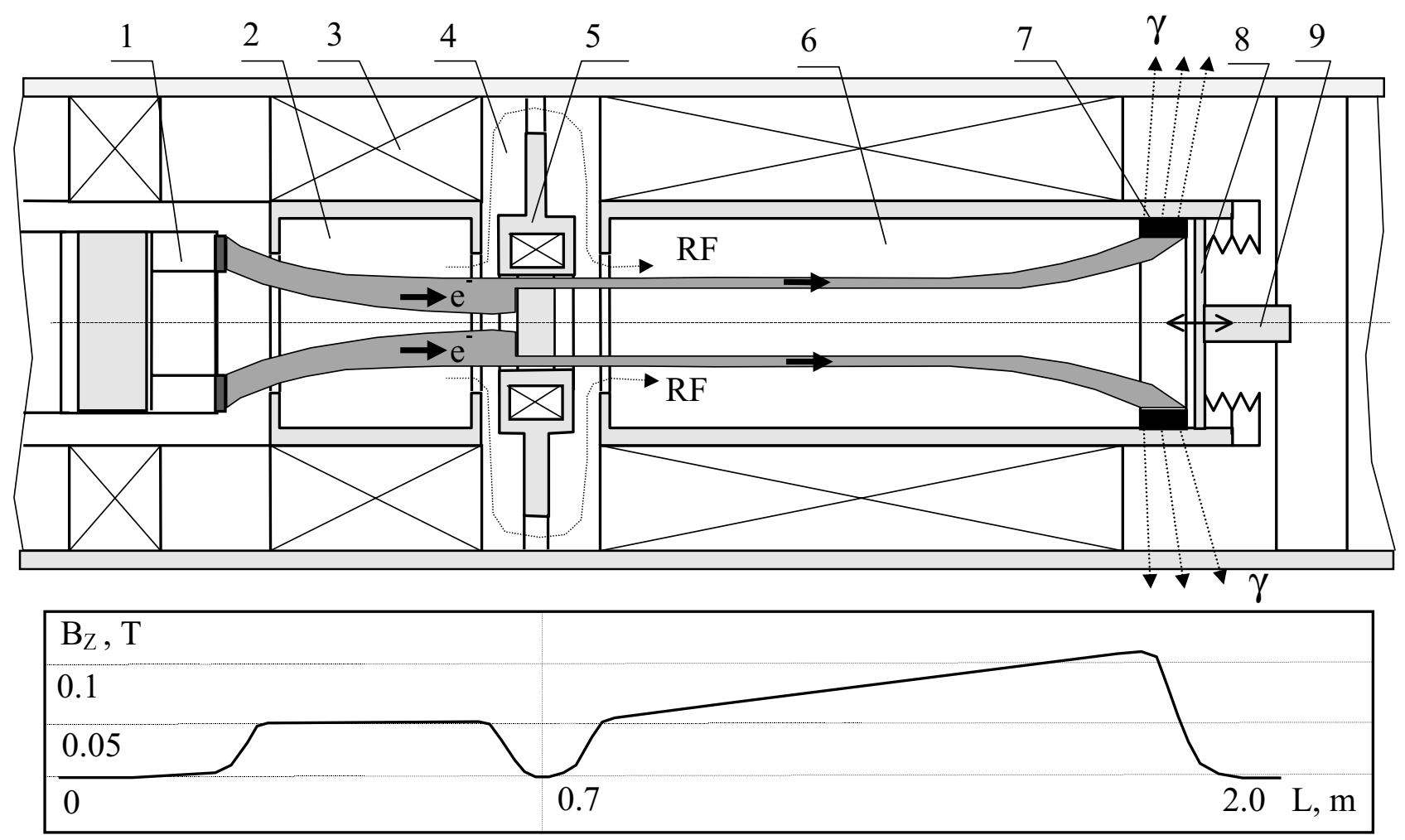

Figure 1: The scheme of device and magnetic field distribution ( 1 - electron source ring cathode;

2 - generating rectangular resonator; 3 - magnetic system coil; 4 - coupling cell (connects generating and accelerating resonator); 5 - collimator of a tubular beam; 6 - accelerating rectangular resonator; 7 - target; 8 - accelerating resonator mobile wall; 9 - reversal engine).

\section{THE CONCLUSIONS}

Precomputations and experiments, carried out in MEPhI and Tomsk Polytechnics Institute, have shown an opportunity of realisation of system proposed. It's electron efficiency can be higher the order in comparison with the induction accelerator, with raise of system durability and bremsstrahlung level increase a more than on the order at the same power consumption.

Nowadays in MEPhI a generating section model is successfully tested and the preliminary model tests of accelerating section were carried out. The model tests of the given acceleration method have confirmed an opportunity of acceleration in operating variant. The electron source current reached $20 \mathrm{~A}$ at voltage up to 100 $\mathrm{kV}$. $\mathrm{LaB}_{6}$ cathode ring has following diameters: external of $30 \mathrm{~mm}$, internal of $10 \mathrm{~mm}$. At a generating section input the rotating electron flow has a diameter about 20 $\mathrm{mm}$. A pulse duration about (80-100) $\mu \mathrm{sec}$, repetition rate is equal to $1 \mathrm{~Hz}$. Numerical optimisation of a magnetic field distribution upon system length will be carried out nowadays.

\section{REFERENCES}

[1] Yu.P. Vahrushin, A.I. Anatcky " Linear induction accelerators ". Moscow, Atomizdat, 1978. (in Russian).

[2] Y.V. Panitchkin, E.T. Protasevitch, Yu.G. Stein "Installation for an experimental research of the charged particles acceleration in smooth waveguides by fast electromagnetic waves at an increasing magnetic field ". Proceedings of Scientific Research Institute of nuclear physics, electronics and automatics at Tomsk Polytechnics Institute, Vol.3, "Charged particles accelerators". Moscow, Atomizdat, 1973, p.p.38-40. (in Russian).

[3] Berezin V.M., Burjak V.S. et al. " UHF electronic devices". Moscow, Vysshaja Shkola, 1985 (in Russian). 